\title{
Multimorbidity in Axial Spondyloarthropathy and Its Association with Disease Outcomes: Results from the Ankylosing Spondylitis Registry of Ireland Cohort
}

\author{
Gillian Fitzgerald (D, Phil Gallagher, and Finbar D. O'Shea (D)
}

ABSTRACT. Objective. Multimorbidity, the coexistence of 2 or more conditions in an individual, is associated with morbidity and mortality in the general population. This study aims to describe the prevalence of multimorbidity in axial spondyloarthropathy (axSpA) and assess its association with disease outcome measures.

Methods. This cross-sectional study was conducted within the Ankylosing Spondylitis Registry of Ireland (ASRI) cohort. Structured standardized assessment was performed. Multimorbidity was considered as the presence of at least 1 physician-diagnosed chronic condition (excluding extraarticular manifestations) in addition to axSpA. Validated outcome measures were collected: Bath Ankylosing Spondylitis Disease Activity Index (BASDAI), Bath AS Functional Index (BASFI), Health Assessment Questionnaire (HAQ), AS Quality of Life (ASQoL), and Bath AS Metrology Index (BASMI). Adjusted multiple regression was performed to investigate the association between multimorbidity and disease outcomes.

Results. A total of 734 patients from 12 centers were included: $77 \%$ male, mean (SD) age 45 (12) years. Of the cohort, $55 \%(\mathrm{n}=403)$ were multimorbid. Multimorbid patients were significantly ( $\mathrm{p}<0.01$ ) older than axSpA-only patients [50 (12) vs 40 (11) yrs]. Obesity was the most prevalent chronic condition, affecting $27 \%$. Multimorbid patients had more severe disease than patients with axSpA only. After adjusting for confounders, multimorbidity was associated with higher BASDAI (ß 0.7, 95\% CI 0.34-1.05), BASMI (B 0.45, 95\% CI 0.09-0.80), BASFI (B 0.5, 95\% CI 0.23-0.78), HAQ ( $0.07,95 \%$ CI 0.00-0.13), and ASQoL ( $0.87,95 \%$ CI $0.28-1.46$ ).

Conclusion. Multimorbidity is prevalent in axSpA and is associated with more severe disease. (First Release October 1 2019; J Rheumatol 2020;47:218-26; doi:10.3899/jrheum.181415)

\section{Key Indexing Terms: SPONDYLOARTHROPATHIES MULTIPLE CHRONIC CONDITIONS}

The dramatic increase in life expectancy of modern times is an important accomplishment ${ }^{1,2}$. Population growth has been accompanied by many challenges ${ }^{3,4}$, including projected increases in age-related expenditure and associated economic

From the Department of Rheumatology, St. James's Hospital; Department of Clinical Medicine, Trinity College Dublin; Department of Rheumatology, St. Vincent's University Hospital, Dublin, Ireland.

The Ankylosing Spondylitis Registry of Ireland (ASRI) is supported by an unrestricted grant from Pfizer Pharmaceuticals and AbbVie

Pharmaceuticals. GF is a recipient of the Bresnihan-Molloy Scholarship from the Royal College of Physicians of Ireland, funded by AbbVie. The funders had no role in the design of the study, collection of the data, analysis, and interpretation of the data, or any part of manuscript preparation.

G. Fitzgerald, MB BCh, BAO, MRCPI, Rheumatologist, PhD candidate, Department of Rheumatology, St. James's Hospital, and Department of Clinical Medicine, Trinity College Dublin; P. Gallagher, RGN, Department of Rheumatology, St. Vincent's University Hospital; F.D. O'Shea, MB BCh, BAO, MRCPI, Consultant Rheumatologist, General Physician,

Department of Rheumatology, St. James's Hospital, and Department of

Clinical Medicine, Trinity College Dublin.

Address correspondence to Dr. G. Fitzgerald, Department of

Rheumatology, St. James's Hospital, Dublin, Ireland.

E-mail: gifitzge@tcd.ie

Accepted for publication May 6, 2019.

\section{AXIAL SPONDYLOARTHOPATHY OUTCOME MEASURES}

burden. A simple aspiration to live longer is no longer the goal. A delayed onset of morbidity and functional decline, termed compression of morbidity ${ }^{5}$, is now the ambition, where people live longer but with less chronic disease. Unfortunately, it appears that old age is instead accompanied by a greater disease burden ${ }^{6}$, in particular noncommunicable diseases, which are now the biggest threats to mortality worldwide ${ }^{7}$.

To cope with aging populations, health systems must $\operatorname{adapt}^{3}$. Current clinical practice guidelines focus on individual comorbidities, without giving adequate guidance on managing patients with multiple chronic conditions ${ }^{8}$. However, with pressure to delay the onset of functional decline and to allow people to remain effective members of society for longer, swapping the concept of comorbidity for multimorbidity is needed ${ }^{8}$. Multimorbidity shifts our focus from a narrow view of considering each condition in isolation to a more holistic approach, whereby the patient is considered as the center of care and all aspects of their condition are considered together ${ }^{8,9}$.

Although the definition can vary, multimorbidity is widely

Personal non-commercial use only. The Journal of Rheumatology Copyright @ 2020 . All rights reserved. 
accepted as the presence of 2 or more chronic conditions in 1 individual, without specifying the index disease ${ }^{10}$. Multimorbidity estimates range from $13 \%$ to $95 \%$, with prevalence increasing with age ${ }^{11,12}$. Multimorbid patients have increased mortality, more disability, worse quality of life, and greater use of healthcare resources ${ }^{13,14,15}$; in some cases, $25 \%$ of the population accounts for more than $50 \%$ of healthcare use ${ }^{15}$. Musculoskeletal disease (MSD) is common in multimorbidity patterns ${ }^{16}$ and serves to intensify the effect ${ }^{17,18}$

In rheumatoid arthritis (RA), $62-65 \%$ of patients are multimorbid ${ }^{19,20}$. Multimorbid patients with RA have worse physical function ${ }^{9}$ and lower rates of disease control $^{21}$.

A growing body of work has examined the burden of comorbidities in axial spondyloarthritis (axSpA) 22,23,24,25,26. Mortality is known to be increased in axSpA patients compared to age- and sex-matched controls ${ }^{25,26,27}$. The Assessment of Spondyloarthritis international SocietyCOMOrbidities in SPondyloArthritis (ASAS-COMOSPA) study ${ }^{23}$ has outlined the comorbidity profile of patients with axSpA, particularly highlighting the frequency of osteoporosis and peptic ulcer disease. Cardiovascular-related comorbidity is also more prevalent in $\mathrm{AS}^{28,29}$. Comorbidity adds to the burden of disease in patients with SpA, reducing physical function and quality of $\operatorname{life}^{24}$. ASAS/European League Against Rheumatism recommendations for management of axSpA suggest that treatment should be tailored to take comorbidities into consideration ${ }^{30}$, but no specific guidelines are available. However, little is known about the burden of multimorbidity in axSpA, despite recognition that better knowledge of multimorbidity is crucial to allow sustainable models of care to be established ${ }^{8}$. In modern society, increasing emphasis is being placed on compression of morbidity; therefore, it is important to understand the effect of multimorbidity in patients with axSpA. To our knowledge, there is no literature looking at the prevalence of multimorbidity and associated relationships in patients with axSpA.

Therefore, the aims of our study are to determine (1) the prevalence of multimorbidity within a well-characterized real-life axSpA cohort, and (2) relationships between multimorbidity and disease outcomes.

\section{MATERIALS AND METHODS}

Ankylosing Spondylitis Registry of Ireland (ASRI) study design and patient recruitment. This study was conducted within the framework of the ASRI cohort. ASRI is a large observational cross-sectional multicenter cohort study, which is ongoing. It was established in 2013, with the primary objective to measure the burden of axSpA disease in the Irish population and identify predictors of poor disease outcome.

Consecutive patients are invited to partake in ASRI if they have a clinical diagnosis of axSpA, made by a rheumatologist, and have attended secondary or tertiary care in the preceding 3 years. Patients are excluded if they have cognitive or other impairment that prohibits informed consent. Each center has a designated subinvestigator with responsibility for local oversight. Accuracy of the data collected is monitored quarterly by (author) PG. The primary investigator (author FOS) has responsibility for overall oversight of the database. To date, 12 centers in Ireland have recruited patients and contributed data to ASRI.

Written informed consent was obtained from all patients. Ethical approval was originally obtained from the Tallaght University Hospital/St. James's Hospital Joint Research Ethics Committee (REC reference: 2013/21/06) and was subsequently approved in each participating center.

Data collection. A trained study investigator collected data according to a standard protocol in a structured face-to-face visit. The medical record was reviewed as required to obtain information not available directly from the patient. The following data were entered into an electronic centralized report form:

- Demographics: age, sex, ethnicity, marital status, employment status, alcohol intake, smoking status (current/past/never), family history of SpA (AS, axSpA, psoriasis, or psoriatic arthritis).

- Disease characteristics: age of symptom onset, duration of disease, delay to diagnosis, history of extraarticular manifestations [EAM; uveitis, psoriasis, inflammatory bowel disease (IBD)], other SpA features (enthesitis, dactylitis, peripheral arthritis), current and previous treatment (nonsteroidal antiinflammatories, methotrexate, sulfasalazine, biologics), HLA-B27 status, highest recorded erythrocyte sedimentation rate (ESR), current ESR (measured on the day), highest recorded C-reactive protein (CRP), current CRP (measured on the day).

- Morbidities: considered present if patient had history of physician diagnosis of any of the following conditions known to be prevalent in $\mathrm{SpA}^{23}$ : ischemic heart disease (IHD), cerebrovascular disease, hypertension (HTN), hyperlipidemia, diabetes mellitus, peptic ulcer disease, tuberculosis, osteoporosis, depression, cancer (melanoma, nonmelanoma skin cancer, lung, breast, gastrointestinal, genitourinary, lymphoma, hematological, other). Additionally, obesity and alcohol excess were noted. Obesity was recorded as a body mass index $>30 \mathrm{mg} / \mathrm{kg}^{2}$, as per the World Health Organization (WHO) criteria, based on the weight and height measurements taken by the investigator during the assessment. Alcohol excess was considered as alcohol consumption $>21$ units/week in men and 14 units/week in women, as per national guidelines ${ }^{31}$, and based on the patient's self-report of alcohol consumption. Patient medical records were used as required to confirm the presence or absence of each of these comorbidities. EAM were not considered as additional morbidities.

- Physical examination: tragus-to-wall, cervical rotation, chest expansion, modified Schober test, lumbar side flexion, intermalleolar distance - all performed according to standardized technique ${ }^{32}$; current blood pressure, height (measured in $\mathrm{cm}$ ), weight (measured in $\mathrm{kg}$ ), waist circumference (measured in $\mathrm{cm}$ ).

- Dual-energy x-ray absorptiometry (DEXA): most recent DEXA result was obtained (if performed) and osteoporosis defined according to $\mathrm{WHO}^{33}$.

Outcome measures. The following validated patient-reported outcomes were collected:

- Bath Ankylosing Spondylitis Disease Activity Index (BASDAI): measured on a scale of $0-10$; higher scores indicate more severe disease ${ }^{34}$.

- Bath AS Functional Index (BASFI): measured on a scale of 0-10; higher scores indicate worse function ${ }^{35}$.

- Health Assessment Questionnaire (HAQ): assessed on a scale of 0-3;0 indicates no disability and 3 indicates large burden of disability ${ }^{36}$.

- AS Quality of Life (ASQoL): assessed on a scale of 0-18; higher scores indicate worse $\mathrm{QOL}^{37}$

- Bath AS Metrology Index (BASMI) assessed spinal mobility on a scale of 0-10; higher scores indicate worse spinal mobility ${ }^{32}$.

Multimorbidity. Morbidity is defined as the presence of a chronic condition in a patient. We defined multimorbidity as the presence of at least 2 chronic conditions in 1 person ${ }^{10,38}$. Severity of multimorbidity was assessed by counting the number of chronic conditions in addition to axSpA present in an individual ${ }^{20,39}$. Of note, EAM were not considered a separate morbidity. Statistical analysis. Descriptive statistics are presented as mean with SD, median with 25 th and 75 th percentiles, or frequencies with percentage as

Personal non-commercial use only. The Journal of Rheumatology Copyright $\subset$ C 2020. All rights reserved. 
appropriate. Independent 2-tailed t tests, Mann-Whitney U test, or ANOVA were performed on continuous data as indicated to examine differences between groups. Chi-square tests compared categorical variables. The Tukey honestly significant difference test controlled for multiple comparisons.

We developed separate models determining the association between (1) being multimorbid, and (2) worsening multimorbidity, defined by number of additional chronic conditions, and disease outcome measures. BASDAI, BASMI, BASFI, ASQoL, and HAQ were individually treated as dependent variables. Initially we investigated univariable demographic, treatment, and disease-related characteristics associated with each outcome. To control for the effects of these characteristics, we built a model using all variables with a $\mathrm{p}$ value $<0.1$ in univariable analysis and performed hierarchical regression, entering variables in blocks of demographics, treatment, and disease-related variables prior to assessing the effect of multimorbidity. Age and sex were controlled for in every model. Adjusted $\mathrm{R}^{2}$ was used to determine the additional variation explained by each block of variables entered. The final models retained variables that significantly improved the fit.

The appropriate assumptions for each statistical test were met. A p value $<0.05$ was considered statistically significant. Statistical analyses were performed using IBM SPSS Statistics version 24 (IBM Corp.).

\section{RESULTS}

Baseline characteristics. At the time of database extraction in February 2018, the ASRI cohort contained 734 patients, from 12 rheumatology centers representing all geographical regions of Ireland. Seventy-seven percent $(n=536)$ of the patients in ASRI are male, with a mean (SD) age of 45 (12) years, and a median (interquartile range) disease duration of 16 (9-27) years. The baseline demographic and clinical characteristics of the ASRI cohort are outlined in Table 1.

Multimorbidity profile of ASRI cohort. Fifty-five percent of the cohort $(n=403)$ are multimorbid (i.e., at least 1 chronic condition in addition to axSpA): $25 \%(\mathrm{n}=180)$ have 1 additional chronic condition, $16 \%(\mathrm{n}=118)$ have 2 additional chronic conditions, $8 \%(n=57)$ have 3 additional chronic conditions, and $7 \%(n=48)$ have 4 or more additional chronic conditions.

The most prevalent chronic condition is obesity, affecting $27 \%$ ( $\mathrm{n}=192$ ) of the population, followed by HTN $(\mathrm{n}=155$, $21 \%)$, hyperlipidemia $(\mathrm{n}=119,16 \%)$, and depression $(\mathrm{n}=76,10 \%)$. Thirty percent $(\mathrm{n}=222)$ of patients have cardiovascular comorbidity (i.e., at least 1 of IHD, cerebrovascular disease, HTN, or hypercholesterolemia). Remaining conditions are outlined in Figure 1.

Thirty-nine patients $(5.3 \%)$ report a prior diagnosis or had a diagnosis recorded in the medical record of osteoporosis. Only $19.5 \%(n=143)$ had previously had a DEXA, of which 95 hip and 94 spine DEXA results were available (results of DEXA performed in private facilities or primary care were not universally available): $58 \%$ had low bone mineral density (BMD) at the hip (43\% osteopenia, $15 \%$ osteoporosis), and $50 \%$ had low BMD at the spine (33\% osteopenia, $17 \%$ osteoporosis).

Comparison of multimorbid and non-multimorbid patients: demographics/clinical characteristics. Multimorbid patients are older, with longer disease duration and longer delay to diagnosis than axSpA-only patients (Table 1). Multimorbid patients have similar CRP and ESR to the axSpA-only cohort. Sex and HLA-B27 status have no effect on the presence or absence of multimorbidity. The prevalence of psoriasis is higher in multimorbid patients than in axSpA-only patients ( $21 \%$ vs $15 \%, p=0.02)$. Uveitis and IBD are equally prevalent in both groups.

Effect of multimorbidity on disease outcomes. Across all disease outcome measures, multimorbid patients have more severe disease than patients with axSpA only (Table 1). Disease outcome measures also correlate with the burden of multimorbidity, which is measured by the number of additional chronic conditions: as the burden of multimorbidity increases, BASDAI scores worsen (see Table 2 for all outcome measures).

The cohort was subsequently compared in 3 groups: (1) axSpA only; (2) multimorbid with 1 additional chronic condition; and (3) multimorbid with 2 or more additional chronic conditions. Disease outcome measures were all significantly higher in patients with multimorbidity compared to patients with axSpA only, regardless of the number of chronic conditions (Table 3). However, when comparing within the patients with multimorbidity, only BASMI, BASFI, and HAQ were significantly higher in patients with 2 or more additional conditions compared to patients with 1 additional condition. There was no difference in BASDAI and ASQoL scores between the multimorbid cohort with 2 or more additional conditions and 1 additional condition (Table 3; ANOVA analysis presented in Supplementary Table 1, available from the authors on request).

Regression analysis: multimorbid versus non-multimorbid. In adjusted analyses (Table 4A), when compared to patients with axSpA only, being multimorbid is associated with a higher BASDAI of 0.7 (95\% CI 0.34-1.05), BASMI of 0.45 (95\% CI 0.09-0.80), BASFI of 0.5 (95\% CI 0.23-0.78), HAQ of 0.07 (95\% CI $0.00-0.13)$, and ASQoL of $0.87(95 \%$ CI 0.28-1.46).

Severity of multimorbidity. In separate models investigating the association between severity of multimorbidity and outcomes (Table 4B), the presence of each additional condition was associated with a higher BASDAI of 0.23 (95\% CI 0.09-0.37), BASMI of 0.20 (95\% CI 0.05-0.34), ASQoL of 0.25 (95\% CI 0.02-0.49), HAQ of 0.03 (95\% CI $0.01-0.06)$, and BASFI of 0.21 (95\% CI $0.10-0.32)$

\section{DISCUSSION}

There is growing interest in multimorbidity. Multimorbid patients have complex needs, requiring cohesive individualized patient-centered strategies rather than the traditional disease-focused model of care, to meet the needs of a rapidly expanding population ${ }^{8}$. The negative consequences of multimorbidity are well outlined in the general population ${ }^{12,13,15}$, but much less is known about its effect in patients with axSpA. Our study found multimorbidity is common in patients with

Personal non-commercial use only. The Journal of Rheumatology Copyright (C) 2020. All rights reserved. 
Table 1. Baseline demographic and clinical characteristics of the cohort according to multimorbidity status.

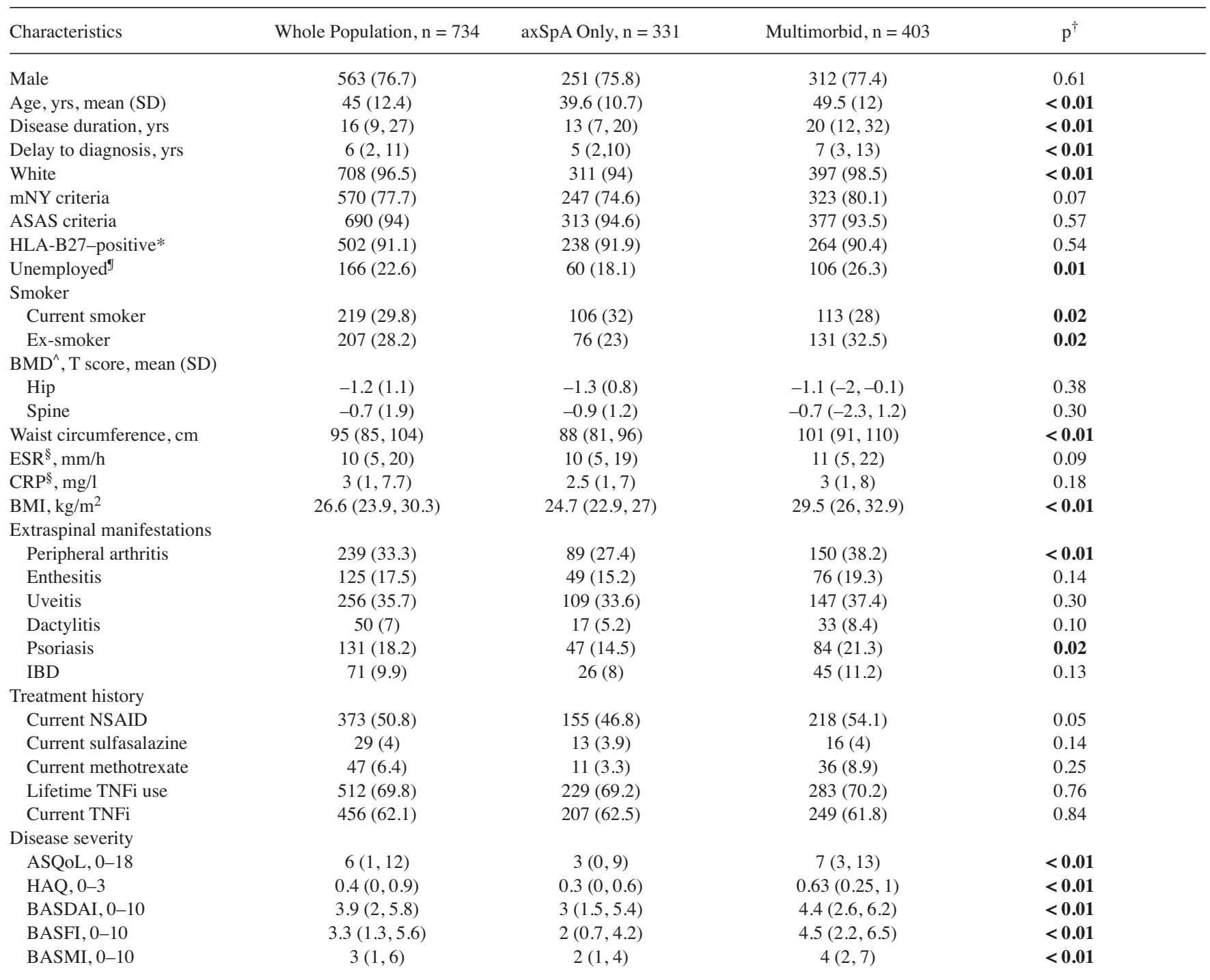

Data are median (25th quartile, 75th quartile), or $\mathrm{n}(\%)$, unless otherwise specified. Values in bold face are statistically significant. * HLA-B27 status unknown in 183 patients. ${ }^{\Phi}$ Patients within employment age but unemployed. ${ }^{\dagger}$ Comparison between axSpA-only and multimorbid patient groups (independent $t$ tests for continuous variables, chi-square analysis for categorical variables). ${ }^{\wedge}$ Most recent BMD results. ${ }^{\S}$ Refers to values at time of recruitment. ASAS: Assessment of Spondyloarthritis international Society; ASQoL: Ankylosing Spondylitis Quality of Life index; axSpA: axial spondyloarthritis; BMD: bone mineral density; HAQ: Health Assessment Questionnaire; IBD: inflammatory bowel disease; mNY: modified New York; NSAID: nonsteroidal antiinflammatory drugs; TNFi: tumor necrosis factor inhibitor; ESR: erythrocyte sedimentation rate; CRP: C-reactive protein; BMI: body mass index; BASDAI: Bath Ankylosing Spondylitis Disease Activity Index; BASFI: Bath Ankylosing Spondylitis Functional Index; BASMI: Bath Ankylosing Spondylitis Metrology Index.

axSpA, affecting over half (55\%) of this large well-characterized cohort. Additionally, multimorbidity is associated with worse disease outcomes than in those with axSpA alone.

The prevalence in our cohort is higher than in the general population, where the prevalence of multimorbidity is around $23 \%{ }^{12}$, although estimates vary from $13 \%$ to $95 \% 11,39$ depending on age group and definition of multimorbidity used. Prevalence of multimorbidity is also higher in primary care populations than the general population ${ }^{40}$. MSD is common in patients with multimorbidity ${ }^{16}$ and multimorbidity is equally prevalent in RA, affecting over $60 \%$ of patients ${ }^{20}$; therefore, it is unsurprising that multimorbidity is common in patients with axSpA.

In our study, we defined the differences between multimorbid and axSpA-only patients. Multimorbid patients with axSpA have longer disease duration, longer delay to diagnosis, and are on average 10 years older than patients with axSpA only, a similar trend to other populations where multimorbidity increases with age ${ }^{12,41}$. However, with multimorbid axSpA patients averaging 50 years, younger than those seen in primary care practice populations and in $\mathrm{RA}^{12,19}$, multimorbidity is not exclusive to the elderly in axSpA.

Personal non-commercial use only. The Journal of Rheumatology Copyright $\odot$ 2020. All rights reserved. 


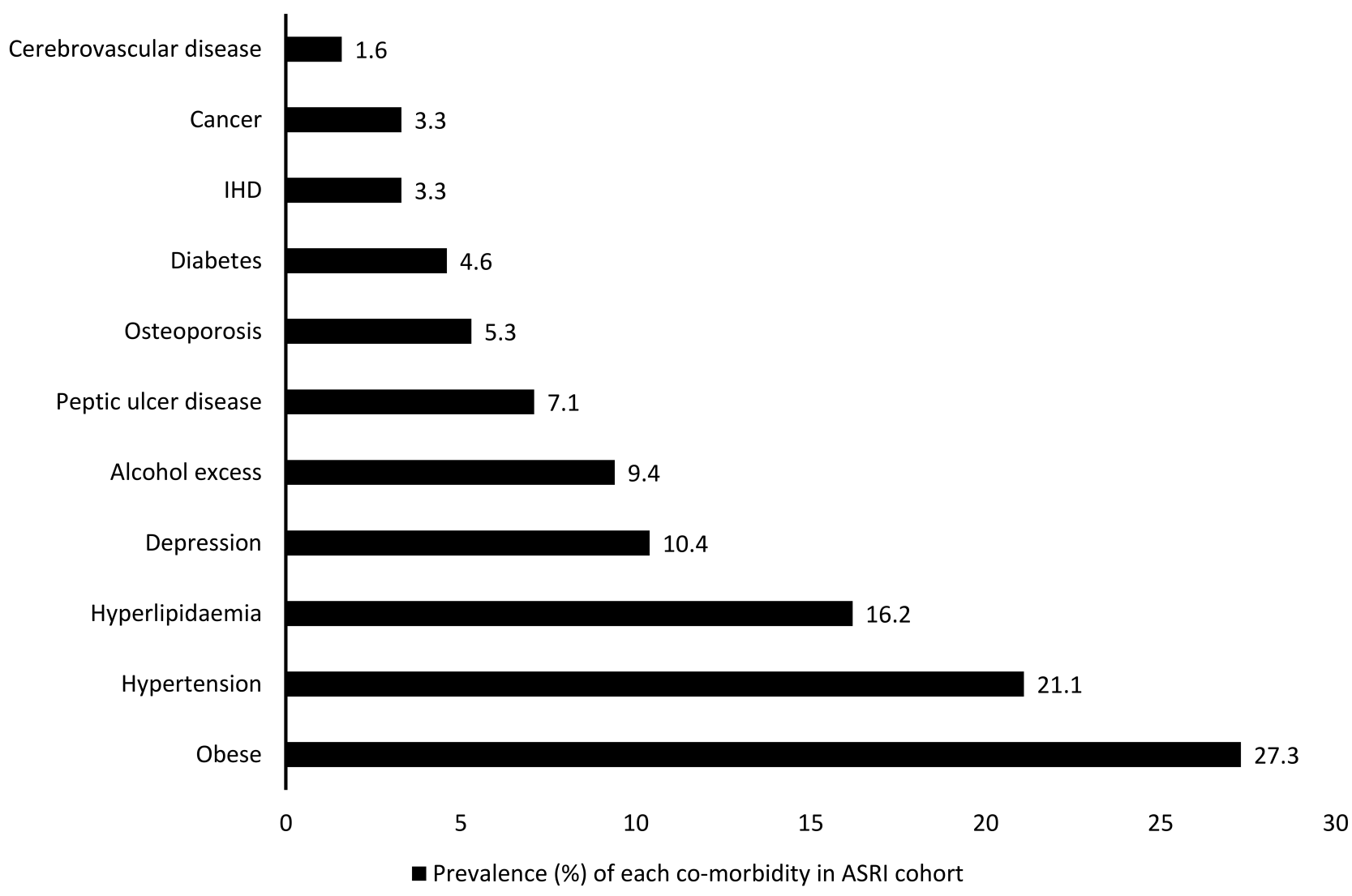

Figure 1. Prevalence of comorbidities in the Ankylosing Spondylitis Registry of Ireland (ASRI), ranked from least to most common. IHD: ischemic heart disease.

Table 2. Relationship between increasing multimorbidity and disease outcome measures.

\begin{tabular}{|c|c|c|c|c|c|}
\hline $\begin{array}{l}\text { Increasing burden } \\
\text { of multimorbidity }\end{array}$ & $\begin{array}{c}0.21 \\
<0.01 \\
725\end{array}$ & $\begin{array}{r}0.36 \\
<0.01 \\
734\end{array}$ & $\begin{array}{c}0.35 \\
<0.01 \\
713\end{array}$ & $\begin{array}{r}0.23 \\
<0.01 \\
732\end{array}$ & $\begin{array}{c}0.27 \\
<0.01 \\
731\end{array}$ \\
\hline
\end{tabular}

Rho: Spearman correlation coefficient; ASQoL: Ankylosing Spondylitis Quality of Life index; BASDAI: Bath Ankylosing Spondylitis Disease Activity Index; BASFI: Bath AS Functional Index; BASMI: Bath AS Metrology Index; HAQ: Health Assessment Questionnaire.

A systematic review of the general population found an association between women and multimorbidity ${ }^{11}$. However, the literature is conflicting in RA, where both no sex effect ${ }^{19}$ and a predominance of women in the multimorbid group ${ }^{42}$ have been shown. Males and females are equally affected by multimorbidity in our study.

Obesity is the most common morbidity, affecting $26 \%$ of our cohort. The prevalences of HTN $(21 \%)$ and hypercholesterolemia $(16 \%)$ are lower in our study than in ASAS-COMOSPA, but frequencies of IHD (3\%) and cerebro- vascular disease $(2 \%)$ are similarly low ${ }^{23}$. Cardiovascular morbidity is common (30\%) in multimorbid patients in our study, reflecting international trends ${ }^{7}$. Depression is prevalent in our study, affecting $10 \%$ of patients, as is alcohol excess $(9 \%)$.

Obesity is not always included in multimorbidity scores; it is counted as a chronic condition in only 5 of 39 multimorbidity counts in a systematic review in $2011^{43}$. However, obesity was not officially recognized as a disease until $2013^{44}$. Because it clearly increases mortality ${ }^{45}$ and repre- 
Table 3. Comparison of disease outcome scores for patients with axSpA only, multimorbid patients with 1 additional condition, and multimorbid patients with 2 or more conditions.

\begin{tabular}{|c|c|c|c|c|c|c|}
\hline \multirow[t]{2}{*}{ Disease Outcome } & \multirow[t]{2}{*}{ Group } & \multirow[t]{2}{*}{$\mathrm{N}$} & \multirow[t]{2}{*}{ Mean } & \multirow[t]{2}{*}{ SD } & \multicolumn{2}{|c|}{ Tukey HSD Comparisons ${ }^{\dagger}$} \\
\hline & & & & & axSpA Only & 1 Additional Condition \\
\hline \multirow[t]{2}{*}{ BASDAI } & axSpA only & 326 & 3.5 & 2.4 & - & - \\
\hline & $\geq 2$ additional conditions & 221 & 4.7 & 2.3 & $<0.01 *$ & 0.16 \\
\hline \multirow[t]{2}{*}{ BASFI } & axSpA only & 331 & 2.7 & 2.4 & - & - \\
\hline & 1 additional condition & 180 & 4.0 & 2.6 & $<0.01 *$ & - \\
\hline & 1 additional condition & 173 & 3.6 & 2.5 & $<0.01^{*}$ & - \\
\hline & $\geq 2$ additional conditions & 218 & 4.8 & 2.6 & $<0.01^{*}$ & $<0.01 *$ \\
\hline \multirow[t]{3}{*}{ ASQoL } & axSpA only & 330 & 5.2 & 5.3 & - & - \\
\hline & 1 additional condition & 179 & 7.5 & 5.5 & $<0.01 *$ & - \\
\hline & $\geq 2$ additional conditions & 223 & 7.9 & 5.7 & $<0.01 *$ & 0.76 \\
\hline HAQ & axSpA only & 330 & 0.39 & 0.45 & - & - \\
\hline
\end{tabular}

${ }^{\dagger}$ P values presented. * Denotes significant difference. - Denotes duplicate cells left blank. ASQoL: Ankylosing Spondylitis Quality of Life index; BASDAI: Bath Ankylosing Spondylitis Disease Activity Index; BASFI: Bath Ankylosing Spondylitis Functional Index; BASMI: Bath Ankylosing Spondylitis Metrology Index; HAQ: Health Assessment Questionnaire; HSD: honestly significant difference; axSpA: axial spondyloarthritis.

Table 4A. Adjusted analyses of association between disease outcome measures, and presence of multimorbidity.

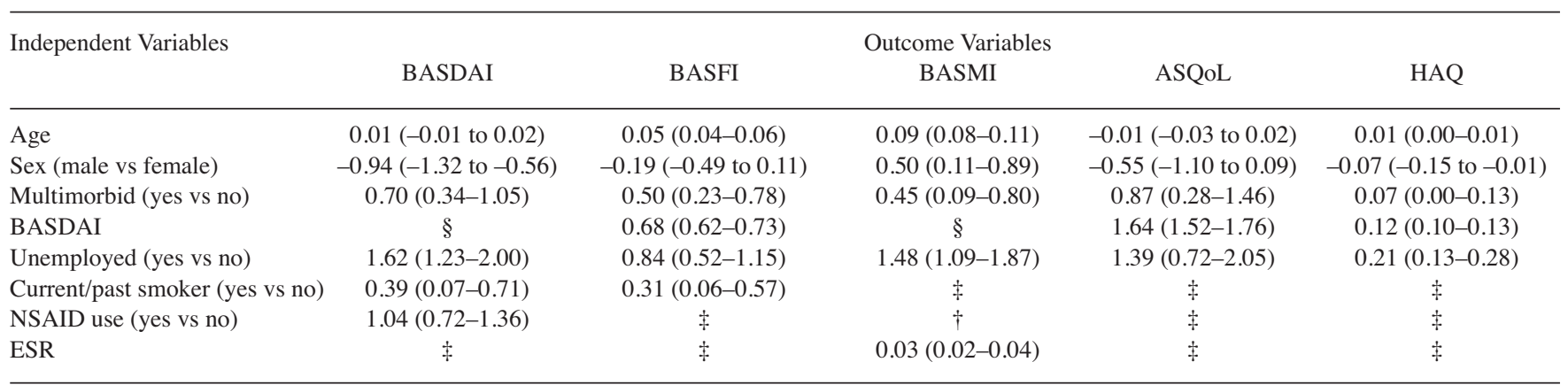

Table $4 B$. Adjusted analyses of association between disease outcome measures and severity of multimorbidity.

\begin{tabular}{|c|c|c|c|c|c|}
\hline Age & 0.01 (-0.01 to 0.02$)$ & $0.05(0.04-0.06)$ & $0.09(0.07-0.11)$ & -0.01 ( -0.03 to 0.02$)$ & $0.01(0.00-0.01)$ \\
\hline Worsening multimorbidity & $0.23(0.09-0.37)$ & $0.21(0.10-0.32)$ & $0.20(0.05-0.34)$ & $0.25(0.02-0.49)$ & $0.03(0.01-0.06)$ \\
\hline BASDAI & $\S$ & $0.73(0.67-0.78)$ & $\S$ & $1.72(1.61-1.84)$ & $0.12(0.11-0.14)$ \\
\hline Delay to diagnosis & $\ddagger$ & $\ddagger$ & & & $-0.01(-0.01-0.00)$ \\
\hline NSAID use (yes vs no) & $1.11(0.79-1.44)$ & $\ddagger$ & $\ddagger$ & $\ddagger$ & $\ddagger$ \\
\hline ESR & $\ddagger$ & $\ddagger$ & $0.03(0.02-0.04)$ & $\ddagger$ & $0.00(0.00-0.01)$ \\
\hline IBD & $0.74(0.19-1.29)$ & $\ddagger$ & $\ddagger$ & $\ddagger$ & $\ddagger$ \\
\hline
\end{tabular}

Values are B $(95 \% \mathrm{CI})$. Variables tested in univariable regression: age, sex, unemployed, delay to diagnosis, current or past smoker, enthesitis, arthritis, dactylitis, uveitis, IBD, psoriasis, CRP, ESR, multimorbid, HLA-B27 positivity, NSAID use, csDMARD use, current TNFi use, lifetime history of TNFi use. Variables not included in the above table were not significant in any final model. Every model controlled for age and sex. $\dagger \mathrm{P}>0.1$ in univariable analysis. $\ddagger \mathrm{P}>0.05$ in multivariable analysis. §: not assessed. ASQoL: Ankylosing Spondylitis Quality of Life index; BASDAI: Bath Ankylosing Spondylitis Disease Activity Index; BASFI: Bath Ankylosing Spondylitis Functional Index; BASMI: Bath Ankylosing Spondylitis Metrology Index; HAQ: Health Assessment Questionnaire; B: regression coefficient; NSAID: nonsteroidal antiinflammatory drug; ESR: erythrocyte sedimentation rate; IBD: inflammatory bowel disease; CRP: C-reactive protein; csDMARD: conventional synthetic disease-modifying antirheumatic drugs; TNFi: tumor necrosis factor inhibitor. 
sents a growing public health challenge, it is worthy of being considered in a multimorbidity count ${ }^{41}$, so we decided to include it.

In ASAS-COMOSPA, osteoporosis was the most frequent comorbidity, affecting $13 \%$ of the cohort ${ }^{23}$. The prevalence of self-reported osteoporosis in our study is $5.3 \%$. However, systematic screening is not feasible in the context of a registry study. Using the DEXA data available in a minority of the cohort, $17 \%$ have osteoporosis. However, this may be an overestimation of the population prevalence, because patients referred for DEXA assessment likely had risk factors making a diagnosis of osteoporosis more probable, thus the true prevalence is expected to fall between 5 and $17 \%$, closer to that reported in ASAS-COMOSPA.

The second aim of this study is to determine the association between multimorbidity and disease outcomes in axSpA. We demonstrate an association between multimorbid patients and worse disease outcomes, using both subjective and objective outcome measures. As the severity of multimorbidity increases, so too do disease outcome scores. Our results reflect the general population, where multimorbidity is associated with impaired function and worse QOL, particularly if a rheumatic disease is involved ${ }^{46}$, and RA, where multimorbid patients have more severe disease and more fatigue than patients with RA only ${ }^{19,47}$. Nikiphorou, et $a l^{24}$ similarly demonstrated that a rising comorbidity burden is associated with worse QOL in patients with SpA.

However, what differentiates our study from those that focus on comorbidity is we demonstrate that simply being multimorbid (i.e., having any additional condition to axSpA) is associated with worse outcomes compared to patients with axSpA alone. The difference in outcomes between axSpA-only and being multimorbid is more marked than the difference for each additional condition thereafter. This has potential to be a clinically useful finding, which could provide physicians with a simple method to identify patients at risk of poor outcomes.

We acknowledge some limitations. First, the crosssectional design of this registry study prohibits comment on causality; therefore, we can merely observe the association between multimorbidity and severe disease. Second, the absence of information on comorbidities not collected within the framework of ASRI represents a potential limitation. However, our study reports the comorbidities known to occur most commonly in SpA, as outlined in ASAS-COMOSPA ${ }^{23}$, with the exception of infections (hepatitis B prevalence of $3.5 \%$ in $\mathrm{SpA}$ worldwide). In Ireland the prevalence of hepatitis B is known to be very low $(<0.1 \%)^{48}$; therefore, it is unlikely to have influenced the results. Additionally, pulmonary disease is not collected in ASRI. However, although abnormalities on high-resolution computed tomography imaging of the thorax are common ${ }^{49}$, the clinical significance of these is unknown ${ }^{50}$; therefore, we are confident that not including a measure of the prevalence of pulmonary disease is unlikely to have significantly affected the prevalence of multimorbidity. Third, alcohol intake is based on the patient's own report. It has been well established that patients tend to underestimate their alcohol consumption. All efforts were made to establish an accurate alcohol intake, but it is possible that intake was underreported, thus underestimating the prevalence of alcohol excess. Fourth, our population is overwhelmingly white; therefore, extrapolating the results of our study to other ethnicities is not possible.

Our study has many strengths. It is a large study, with a well-characterized cohort. The homogeneous characteristics of our patients reduces variation that could be introduced from diverse backgrounds. Additionally, it contains real-life data, providing clinicians with relevant and clinically useful information. It is also novel, as the first study to examine prevalence estimates of multimorbidity in axSpA, to our knowledge. To date, studies have primarily focused on individual comorbidities in axSpA, along with their effect on disease outcomes/management. Focusing on individual conditions takes the focus away from the patient; different conditions are considered the index disease by different clinicians, all aiming for best control of their disease of interest, without necessarily considering its effect on other diseases, potentially leading to fragmented care ${ }^{8,9}$. Multimorbidity brings the focus back to the patient, not the disease. Further research is needed to further delineate the effect of multimorbidity in our patients. Specifically, prospective longitudinal studies are needed to investigate the development of multimorbidity in axSpA and its effect on disease outcomes over time.

We have demonstrated that multimorbidity is prevalent in patients with axSpA and that the presence of multimorbidity is associated with worse disease outcomes.

\section{ACKNOWLEDGMENT}

This study was conducted on behalf of the steering committee of the ASRI We thank all the patients for participating in this study. We also thank all the personnel in the centers who so willingly and enthusiastically contributed, and continue to contribute, data to ASRI: Blackrock Clinic, Cork University Hospital, Galway University Hospitals, Midland Regional Hospital Tullamore, Our Lady's Hospital Manorhamilton, Our Lady's Hospital Navan, St. James's Hospital, St. Vincent's University Hospital, Tallaght University Hospital, University Hospital Kerry, University Hospital Limerick, and University Hospital Waterford.

\section{REFERENCES}

1. European Commission. The 2015 Ageing Report: economic and budgetary projections for the 28 EU member states (2013-2060). [Internet. Accessed August 21, 2019.] Available from: ec.europa.eu/economy_finance/publications/european_economy/ 2015/pdf/ee3_en.pdf

2. Arias E, Heron M, Xu J. United States life tables, 2013. Natl Vital Stat Rep 2017;66:1-64.

3. Rechel B, Grundy E, Robine JM, Cylus J, Mackenbach JP, Knai C, et al. Ageing in the European Union. Lancet 2013;381:1312-22.

4. Christensen K, Doblhammer G, Rau R, Vaupel JW. Ageing populations: the challenges ahead. The Lancet 2009;374:1196-208.

Personal non-commercial use only. The Journal of Rheumatology Copyright $\odot$ 2020. All rights reserved 
5. Fries JF. The compression of morbidity. Milbank Mem Fund Q Health Soc 1983;61:397-419.

6. Pefoyo AJ, Bronskill SE, Gruneir A, Calzavara A, Thavorn K, Petrosyan Y, et al. The increasing burden and complexity of multimorbidity. BMC Public Health 2015;15:415.

7. World Health Organization. Global status report on noncommunicable diseases 2014. [Internet. Accessed August 21, 2019.] Available from: www.who.int/nmh/publications/ ncd-status-report-2014/en

8. Navickas R, Petric VK, Feigl AB, Seychell M. Multimorbidity: what do we know? What should we do? J Comorb 2016;6:4-11.

9. Radner H, Yoshida K, Smolen JS, Solomon DH. Multimorbidity and rheumatic conditions-enhancing the concept of comorbidity. Nat Rev Rheumatol 2014;10:252-6.

10. Almirall J, Fortin M. The coexistence of terms to describe the presence of multiple concurrent diseases. J Comorb 2013;3:4-9.

11. Violan C, Foguet-Boreu Q, Flores-Mateo G, Salisbury C, Blom J, Freitag M, et al. Prevalence, determinants and patterns of multimorbidity in primary care: a systematic review of observational studies. PLoS One 2014;9:e102149.

12. Barnett K, Mercer SW, Norbury M, Watt G, Wyke S, Guthrie B. Epidemiology of multimorbidity and implications for health care, research, and medical education: a cross-sectional study. Lancet 2012;380:37-43

13. Menotti A, Mulder I, Nissinen A, Giampaoli S, Feskens EJ, Kromhout D. Prevalence of morbidity and multimorbidity in elderly male populations and their impact on 10-year all-cause mortality: The FINE study (Finland, Italy, Netherlands, Elderly). J Clin Epidemiol 2001;54:680-6.

14. McDaid O, Hanly MJ, Richardson K, Kee F, Kenny RA, Savva GM. The effect of multiple chronic conditions on self-rated health, disability and quality of life among the older populations of Northern Ireland and the Republic of Ireland: a comparison of two nationally representative cross-sectional surveys. BMJ Open 2013;3: e002571.

15. Cassell A, Edwards D, Harshfield A, Rhodes K, Brimicombe J, Payne R, et al. The epidemiology of multimorbidity in primary care: a retrospective cohort study. Br J Gen Pract 2018; 68:e245-51.

16. Simoes D, Araujo FA, Severo M, Monjardino T, Cruz I, Carmona L, et al. Patterns and consequences of multimorbidity in the general population: there is no chronic disease management without rheumatic disease management. Arthritis Care Res 2017;69:12-20.

17. van der Zee-Neuen A, Putrik P, Ramiro S, Keszei A, de Bie R, Chorus A, et al. Impact of chronic diseases and multimorbidity on health and health care costs: the additional role of musculoskeletal disorders. Arthritis Care Res 2016;68:1823-31.

18. Duffield SJ, Ellis BM, Goodson N, Walker-Bone K, Conaghan PG, Margham T, et al. The contribution of musculoskeletal disorders in multimorbidity: implications for practice and policy. Best Pract Res Clin Rheumatol 2017;31:129-44.

19. Radner H, Yoshida K, Hmamouchi I, Dougados M, Smolen JS, Solomon DH. Treatment patterns of multimorbid patients with rheumatoid arthritis: results from an international cross-sectional study. J Rheumatol 2015;42:1099-104.

20. Radner H, Yoshida K, Mjaavatten MD, Aletaha D, Frits M, Lu B, et al. Development of a multimorbidity index: impact on quality of life using a rheumatoid arthritis cohort. Semin Arthritis Rheum 2015;45:167-73.

21. Radner H, Yoshida K, Frits M, Iannaccone C, Shadick NA, Weinblatt $\mathrm{M}$, et al. The impact of multimorbidity status on treatment response in rheumatoid arthritis patients initiating disease-modifying anti-rheumatic drugs. Rheumatology 2015;54:2076-84.

22. Walsh JA, Song X, Kim G, Park Y. Evaluation of the comorbidity burden in patients with ankylosing spondylitis using a large US administrative claims data set. Clin Rheumatol 2018;37:1869-78.

23. Molto A, Etcheto A, van der Heijde D, Landewe R, van den Bosch F, Bautista Molano W, et al. Prevalence of comorbidities and evaluation of their screening in spondyloarthritis: results of the international cross-sectional ASAS-COMOSPA study. Ann Rheum Dis 2016;75:1016-23

24. Nikiphorou E, Ramiro S, van der Heijde D, Norton S, Molto A, Dougados M, et al; Assessment of SpondyloArthritis International Society Comorbidities in Spondyloarthritis Study Task Force. Association of comorbidities in spondyloarthritis with poor function, work disability, and quality of life: results from the Assessment of SpondyloArthritis International Society Comorbidities in Spondyloarthritis study. Arthritis Care Res 2018;70:1257-62.

25. Haroon NN, Paterson JM, Li P, Inman RD, Haroon N. Patients with ankylosing spondylitis have increased cardiovascular and cerebrovascular mortality: a population-based study. Ann Intern Med 2015;163:409-16.

26. Exarchou S, Lie E, Lindstrom U, Askling J, Forsblad-d'Elia H, Turesson C, et al. Mortality in ankylosing spondylitis: results from a nationwide population-based study. Ann Rheum Dis 2016; 75:1466-72.

27. Bakland G, Gran JT, Nossent JC. Increased mortality in ankylosing spondylitis is related to disease activity. Ann Rheum Dis 2011;70:1921-5.

28. Ahmed N, Prior JA, Chen Y, Hayward R, Mallen CD, Hider SL Prevalence of cardiovascular-related comorbidity in ankylosing spondylitis, psoriatic arthritis and psoriasis in primary care: a matched retrospective cohort study. Clin Rheumatol 2016; 35:3069-73.

29. Bremander A, Petersson IF, Bergman S, Englund M. Population-based estimates of common comorbidities and cardiovascular disease in ankylosing spondylitis. Arthritis Care Res 2011;63:550-6

30. van der Heijde D, Ramiro S, Landewe R, Baraliakos X, Van den Bosch F, Sepriano A, et al. 2016 update of the ASAS-EULAR management recommendations for axial spondyloarthritis. Ann Rheum Dis 2017;76:978-91.

31. Health Service Executive. About the alcohol programme - healthy Ireland. [Internet. Accessed August 21, 2019.] Available from: www.hse.ie/eng/health/hl/change/alcohol

32. Jenkinson TR, Mallorie PA, Whitelock HC, Kennedy LG, Garrett SL, Calin A. Defining spinal mobility in ankylosing spondylitis (AS). The Bath AS Metrology Index. J Rheumatol 1994;21:1694-8.

33. Consensus development conference: diagnosis, prophylaxis, and treatment of osteoporosis. Am J Med 1993;94:646-50

34. Garrett S, Jenkinson T, Kennedy LG, Whitelock H, Gaisford P, Calin A. A new approach to defining disease status in ankylosing spondylitis: the Bath Ankylosing Spondylitis Disease Activity Index. J Rheumatol 1994;21:2286-91.

35. Calin A, Garrett S, Whitelock H, Kennedy LG, O'Hea J, Mallorie P et al. A new approach to defining functional ability in ankylosing spondylitis: the development of the Bath Ankylosing Spondylitis Functional Index. J Rheumatol 1994;21:2281-5.

36. Fries JF, Spitz P, Kraines RG, Holman HR. Measurement of patient outcome in arthritis. Arthritis Rheum 1980;23:137-45.

37. Doward LC, Spoorenberg A, Cook SA, Whalley D, Helliwell PS, Kay LJ, et al. Development of the ASQoL: a quality of life instrument specific to ankylosing spondylitis. Ann Rheum Dis 2003;62:20-6

38. van den Akker M, Buntinx F, Knottnerus JA. Comorbidity or multimorbidity: what's in a name? A review of literature. Eur J Gen Pract 1996;2:65-70.

39. Hanlon P, Nicholl BI, Jani BD, Lee D, McQueenie R, Mair FS. Frailty and pre-frailty in middle-aged and older adults and its

Personal non-commercial use only. The Journal of Rheumatology Copyright (C) 2020. All rights reserved. 
association with multimorbidity and mortality: a prospective analysis of 493737 UK Biobank participants. Lancet Public Health 2018;3:e323-32.

40. Mokraoui NM, Haggerty J, Almirall J, Fortin M. Prevalence of self-reported multimorbidity in the general population and in primary care practices: a cross-sectional study. BMC Res Notes 2016;9:314.

41. Agborsangaya CB, Ngwakongnwi E, Lahtinen M, Cooke T, Johnson JA. Multimorbidity prevalence in the general population: the role of obesity in chronic disease clustering. BMC Public Health 2013;13:1161.

42. Armagan B, Sari A, Erden A, Kilic L, Erdat EC, Kilickap S, et al. Starting of biological disease modifying antirheumatic drugs may be postponed in rheumatoid arthritis patients with multimorbidity: single center real life results. Medicine 2018;97:e9930.

43. Diederichs C, Berger K, Bartels DB. The measurement of multiple chronic diseases - a systematic review on existing multimorbidity indices. J Gerontol A Biol Sci Med Sci 2011;66:301-11.

44. Kyle TK, Dhurandhar EJ, Allison DB. Regarding obesity as a disease: evolving policies and their implications. Endocrinol Metab Clin North Am 2016;45:511-20.

45. Flegal KM, Kit BK, Orpana H, Graubard BI. Association of all-cause mortality with overweight and obesity using standard body mass index categories: a systematic review and meta-analysis. JAMA 2013;309:71-82.
46. Loza E, Jover JA, Rodriguez L, Carmona L; EPISER Study Group. Multimorbidity: prevalence, effect on quality of life and daily functioning, and variation of this effect when one condition is a rheumatic disease. Semin Arthritis Rheum 2009;38:312-9.

47. Tournadre A, Pereira B, Gossec L, Soubrier M, Dougados M. Impact of comorbidities on fatigue in rheumatoid arthritis patients: results from a nurse-led program for comorbidities management (COMEDRA). Joint Bone Spine 2019;86:55-60.

48. Schweitzer A, Horn J, Mikolajczyk RT, Krause G, Ott JJ. Estimations of worldwide prevalence of chronic hepatitis B virus infection: a systematic review of data published between 1965 and 2013. Lancet 2015;386:1546-55.

49. El Maghraoui A, Dehhaoui M. Prevalence and characteristics of lung involvement on high resolution computed tomography in patients with ankylosing spondylitis: a systematic review. Pulm Med 2012;2012:965956.

50. Ozdemir O, Gulsun Akpinar M, Inanici F, Hascelik HZ. Pulmonary abnormalities on high-resolution computed tomography in ankylosing spondylitis: relationship to disease duration and pulmonary function testing. Rheumatol Int 2012;32:2031-6. 